\title{
Influence of Epidural Needle Treatment at the Heel of the Bevel on Catheter Breakage
}

\author{
Genya Urimoto*, Kenji Ito, Keiichiro Saito, Suhei Tetsu, Kai Yamazaki, Toshiyasu Suzuki \\ Department of Anesthesiology, Tokai University School of Medicine, Isehara City, Japan \\ Email: * genya @is.icc.u-tokai.ac.jp
}

How to cite this paper: Urimoto, G., Ito, K., Saito, K., Tetsu, S., Yamazaki, K. and Suzuki, T. (2019) Influence of Epidural Needle Treatment at the Heel of the Bevel on Catheter Breakage. Open Journal of Anesthesiology, 9, 1-7.

https://doi.org/10.4236/ojanes.2019.91001

Received: December 4, 2018

Accepted: January 12, 2019

Published: January 15, 2019

Copyright (c) 2019 by author(s) and Scientific Research Publishing Inc. This work is licensed under the Creative Commons Attribution International License (CC BY 4.0).

http://creativecommons.org/licenses/by/4.0/

\begin{abstract}
Background: Epidural anesthesia continues to play a central role in postoperative analgesia. Epidural catheter breakage and fragment retention in the body is a complication related to epidural anesthesia. To reduce the risk of epidural catheter damage by epidural needles, needles with special changes to the heel of the bevel are commercially available. The present study aimed to assess the effectiveness of blasting and drilling treatments at the heel of the epidural needle bevel to determine which treatment is more appropriate. Methods: The epidural needles with blasting, drilling, or no treatment to the heel of the bevel were prepared. The catheter was pulled out from the tip of the epidural needle, folded back $180^{\circ}$, and then pulled up at a speed of 400 $\mathrm{mm} / \mathrm{min}$ until it was fractured. The force needed to break the catheter (FB) was measured. Subsequently, low-density polyethylene $(0.05 \mathrm{~mm})$ was vertically penetrated with the needles at a speed of $200 \mathrm{~mm} / \mathrm{min}$, and the maximum force at penetration (FP) was measured. Results: The FB values for the blasted, drilled, and control needles were $21.3,12.23$, and $6.27 \mathrm{~N}$, respectively ( $\mathrm{p}<0.01$ ). The FP values for the blasted, drilled, and control needles were $0.82,0.69$, and $0.73 \mathrm{~N}$, respectively. Conclusion: Blasting treatment is the most effective approach for the prevention of catheter rupture; however, it can increase the puncture force.
\end{abstract}

\section{Keywords}

Catheter Rupture, Epidural Needle, Blasting, Drilling

\section{Introduction}

Various postoperative analgesia methods have been proposed and developed in recent years, but epidural anesthesia continues to play a central role in postoperative analgesia and has been reported to be an effective analgesic tool. Complica- 
tions related to epidural catheter placement, including epidural catheter breakage and fragment retention in the body, have been reported. A retained broken catheter was first reported by Bonica et al. [1], and since then, it has been sporadically reported in the literature [1]. Recently, the frequency of occurrence was reported to be 1 in 1818 cases [2]. Catheters that remain in the body are normally asymptomatic and rarely require surgical extraction; however, they sometimes cause neurological symptoms, requiring surgery [3].

Catheter rupture generally occurs at the time of removal. When a knot forms or when the catheter gets stuck at the spinous process or vertebral arch, forcible extraction can cause catheter rupture [4] [5] [6]. Another factor that contributes to catheter breakage is catheter damage during insertion. If only the catheter is moved without changing the position of the epidural needle simultaneously or if the position of the needle is changed while the catheter is still out of the needle tip, the catheter might break or become damaged during insertion. In such a situation, the catheter is hypothetically considered to be broken by being pinched between hard tissue and the heel of the epidural needle bevel [7]. It has been reported that this cause of catheter rupture and guide-wire issues during central venous catheter insertion have a similar mechanism [8]. Therefore, to reduce the risk of epidural catheter damage by epidural needles, needles with special changes to the heel of the bevel are commercially available. Blasting and drilling treatments are usually performed to create changes at the heel. Blasting involves blowing fine particles onto the heel at high speed, and drilling involves filing the edge and the inner side of the heel of the bevel by scraping with a metal rod rotating at high speed. However, these treatments may increase frictional resistance of the surface and make the needle bevel blunt, which may lead to an increase in the needle puncture force.

We assessed the effectiveness of blasting and drilling treatments at the heel of the epidural needle bevel to determine which treatment is more appropriate. In addition, we examined whether these treatments at the heel affect the needle puncture force.

\section{Methods}

We prepared 18-gage 96.5-mm-long Tuohy needles (Unisis, Tokyo, Japan) without inner stylets. Blasting and drilling treatments were applied to the heel of the bevel, and those needle treatments were performed by Unisis Corporation. The blasted needle (BN) was processed with minute beads blown at high speed onto the heel, whereas the drilled needle (DN) was processed with a drill rotating at high speed to file the edge and inner side of the heel. The control needle (CN) did not receive any treatment at the heel. The measured dimensions of the needles are presented in Table 1, schematic views are presented in Figure 1, and magnified external views of the heel are presented in Figure 2. As the size of each needle was within the standard value, we assumed that the condition of each needle, other than the difference with regard to the treatment at the heel, was equivalent. 
Table 1. Measurements of each needle.

\begin{tabular}{cccccccc}
\hline & $\begin{array}{c}\text { Outer } \\
\text { diameter } \\
(\mathrm{mm})\end{array}$ & $\begin{array}{c}\text { Inner } \\
\text { diameter } \\
(\mathrm{mm})\end{array}$ & $\begin{array}{c}\text { Thickness } \\
(\mathrm{mm})\end{array}$ & $\alpha\left(^{\circ}\right)$ & $\beta\left(^{\circ}\right)$ & $\begin{array}{c}\text { Height } \\
(\mathrm{mm})\end{array}$ & $\begin{array}{c}\text { Bevel } \\
\text { length } \\
(\mathrm{mm})\end{array}$ \\
\hline $\begin{array}{c}\text { Specification } \\
\text { value } \\
\begin{array}{c}\text { Allowable } \\
\text { range }\end{array}\end{array}$ & 1.27 & 1.07 & - & 9 & 19 & 1.400 & - \\
$\begin{array}{c}\text { Blasted needle } \\
\text { Drilled needle }\end{array}$ & 1.02 to -0.01 & 0.02 to -0.01 & - & +2 to -1 & +2 to -1 & +0.20 to 0 & - \\
Control needle & 1.28 & 1.06 & 0.11 & 10.06 & 18.10 & 1.412 & 2.943 \\
\hline
\end{tabular}

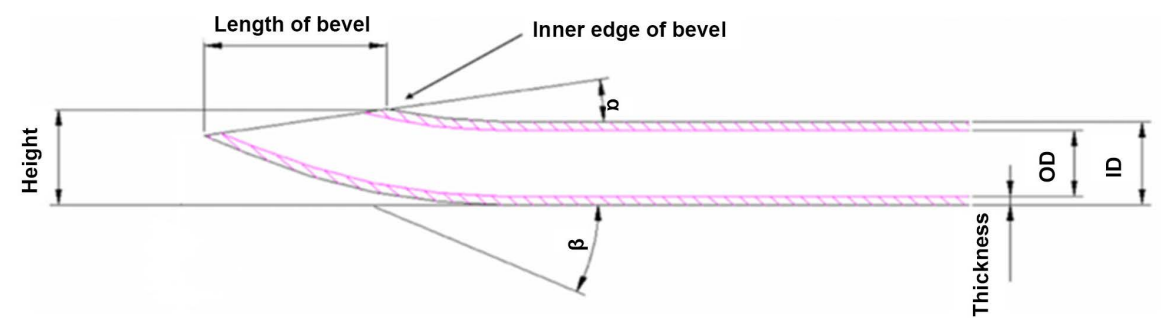

Figure 1. Schematic of an epidural needle.
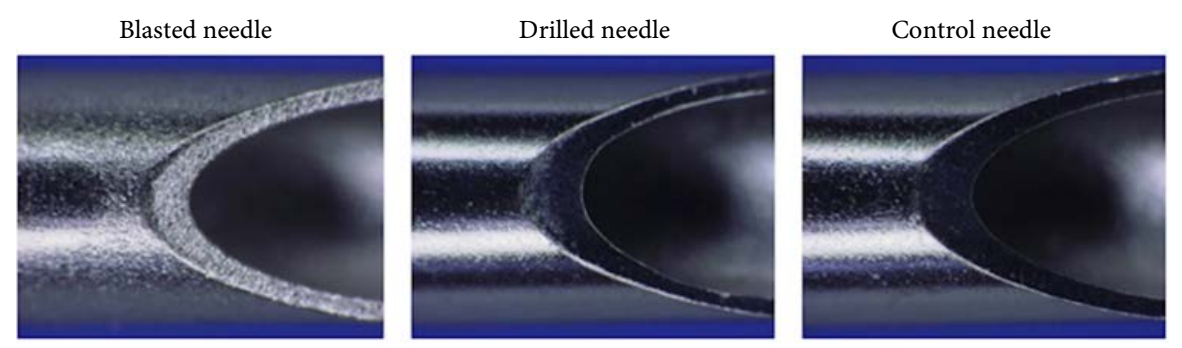

Figure 2. 175 times magnified images of the heels of the different needles.

We initially investigated whether the two different treatments of the heel of the bevel, blasting and drilling, were appropriate for the prevention of catheter rupture. For assessment, we conducted a laboratory study. A compact tabletop tester (EZ-Test, Shimadzu, Kyoto, Japan) was used to measure the breaking force of the catheter. The epidural needle was fixed vertically on the tester. The catheter (Unisis ${ }^{\circledast} 22 \mathrm{G}, 900 \mathrm{~mm}$, polyurethane) was pulled out from the tip of the needle and was folded back $180^{\circ}$, and one side of the catheter was fixed while another side was gripped by the jig of the tester. The catheter was then pulled up at a speed of $400 \mathrm{~mm} / \mathrm{min}$ until it was fractured. The force needed to break the catheter (FB) was measured. This experiment was repeated 10 times with each needle. Additionally, we investigated the durability of the catheter itself without the needle. The catheter with one end fixed was pulled up by the tester until it was sheared, and the force (FB catheter) was measured.

We subsequently measured the puncture force. A precision universal tester (Autograph AG-1, Shimadzu) was used to measure the puncture force. The epidural needle without a stylet was vertically set in the tester. Then, a low-density 
polyethylene film ( $0.05 \mathrm{~mm}$; Nipolon ${ }^{\circledR} 183$, Tosoh, Tokyo, Japan) was vertically penetrated at a speed of $200 \mathrm{~mm} / \mathrm{min}$, and the maximum force at penetration (FP) was measured. We adjusted the needle speed to $200 \mathrm{~mm} / \mathrm{min}$ because it was visually identical with the speed of clinical use. Each needle penetrated the film 10 times.

One-way ANOVA was carried out with GraphPad Prism 7 (GraphPad Software Inc., San Diego, CA, USA), and Turkey's test was used for multiple comparisons. A p-value $<0.05$ was considered to indicate a significant difference.

\section{Results}

The FB of each needle is presented in Table 2, and images of the cut surfaces magnified 100 times are shown in Figure 3. The FB of the BN $(21.30 \mathrm{~N})$ was significantly greater than that of the DN $(12.23 \mathrm{~N})$ and $\mathrm{CN}(6.27 \mathrm{~N})(\mathrm{p}<0.01)$. The $\mathrm{FB}$ catheter, which was the force required to break the catheter without a needle, was $24.00 \mathrm{~N}$, and the magnitude of the force was almost equal to that of the BN. Therefore, blasting treatment was considered very effective for the prevention of breakage. The $\mathrm{FB}$ of the $\mathrm{DN}$ was smaller than that of the $\mathrm{BN}$ but was significantly larger than that of the $\mathrm{CN}$. The cut of the catheter by the $\mathrm{CN}$ appeared smooth and resembled a cut by a blade, but the cuts of the catheters by the BN and DN were irregular, and hence, the blasting and drilling treatments at the heel were considered to be effective (Figure 3 ).

The FP exhibited a bimodal waveform with two peaks (Table 3). The first peak was formed when passing through the tip, and the second peak was formed when passing through the heel. The first peaks of the $\mathrm{BN}, \mathrm{DN}$, and $\mathrm{CN}$ were equivalent to $0.42,0.42$, and $0.44 \mathrm{~N}$, respectively. The second peaks of the $\mathrm{BN}$, $\mathrm{DN}$, and $\mathrm{CN}$ were equivalent to $0.82,0.69$, and $0.73 \mathrm{~N}$, respectively. The FP of the $\mathrm{BN}$ was the largest $(\mathrm{p}<0.01)$, and there was no significant difference in the value between the DN and CN (Table 3).

\section{Discussion}

Retention of an epidural catheter inside the body is uncommon, but some cases have been occasionally reported. To our knowledge, this is the first study to examine the influence of epidural needle treatment at the heel of the bevel on epidural catheter rupture. We found that the FB of the $\mathrm{BN}$ was larger than that of the $\mathrm{DN}$, and the intensity was almost equivalent to the force needed to break the catheter without a needle. Thus, blasting treatment at the heel was more effective than drilling treatment as an approach to prevent catheter breakage. Nevertheless,

Table 2. The force of each needle needed to break the catheter.

\begin{tabular}{lcccc}
\hline & Blasted needle & Drilled needle & Control needle & Catheter only \\
\hline FB (mean [SD]) (N) & $21.30(1.54)^{* *}$ & $12.23(2.05)^{* *}$ & $6.27(0.75)^{* *}$ & $24.00(2.23)^{* *}$ \\
\hline
\end{tabular}

${ }^{* *} \mathrm{p}<0.01$. FB: the force needed to break the catheter, catheter only: the force needed to break the catheter without a needle. Each value was significantly different between groups. 
Table 3. Data of the maximum force at penetration.

\begin{tabular}{cccc}
\hline & Blasted needle & Drilled needle & Control needle \\
\hline $\begin{array}{c}\text { FP 1st peak } \\
(\text { mean [SD]) (N) }\end{array}$ & $0.42(0.02)$ & $0.44(0.05)$ & $0.42(0.02)$ \\
$\begin{array}{c}\text { FP 2nd peak } \\
\text { (mean [SD]) (N) }\end{array}$ & $0.82(0.04) * *$ & $0.69(0.02)$ & $0.73(0.03)$ \\
\hline
\end{tabular}

${ }^{* *} \mathrm{p}<0.01$. FP 1st peak: the maximum force measured when the tip of the needle penetrated the film. FP 2nd peak: the maximum force measured when the heel of the needle penetrated the film. There was no significant difference among needles in FP 1st peak. In FP 2nd peak, FP of blasted needle was the largest compared to drilled needle and control needle $(\mathrm{p}<0.01)$.

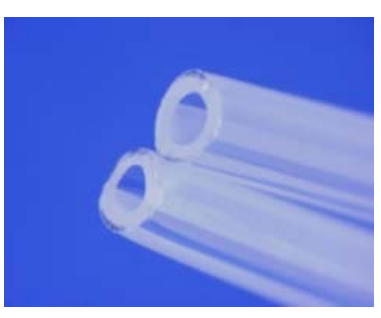

(a)

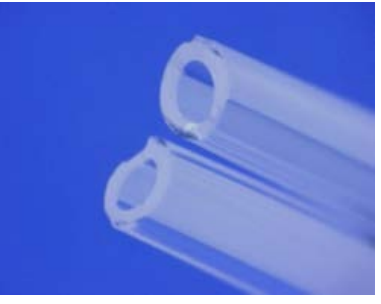

(b)

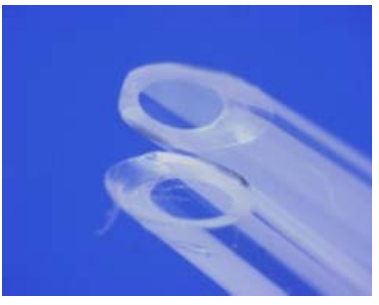

(c)

Figure 3. The catheter surface cut by the blasted needle (a), drilled needle (b), and control needle (c). The images were magnified 100 times.

drilling treatment was effective, as the FB was significantly greater than the control $\mathrm{FB}$, indicating that drilling treatment can prevent catheter breakage to a certain extent. When treatment was not applied to the heel, the FB was significantly smaller and the cut of the catheter appeared smooth and resembled a cut by a blade. Therefore, to decrease the frequency of epidural catheter retention, some effective treatment is necessary at the heel of the epidural needle. We examined whether treatment at the heel has some effect on the needle puncture force. The first peak of the waveform in the puncture force experiment, which was obtained when the needle tip passed through the film, had almost the same value among the three needles. The second peak of the waveform, which was obtained when the needle heel passed through the film, had a significantly higher value in the $\mathrm{BN}$ than in the DN and $\mathrm{CN}$. The surface of the BN appeared rough (Figure 2), which caused high frictional resistance when penetrating tissue. We confirmed that the blasting treatment made the epidural needle slightly dull. Although this characteristic of the BN may not act as a disadvantage because there is no universally clear standard for the sharpness of the Tuohy needle, having a reasonable penetration force may be advantageous for sensing the unique texture of the ligamentum flavum before the needle tip reaches the epidural space. In the catheter experiment, we did not exchange the needle every time the catheter broke. Thus, repeated rupture of the catheter may have caused the heel to become blunt and may have affected the results. However, as there was no tendency for the FB to rise each time the number of catheter ruptures increased, the effect of blunting is considered small in this experimental system. In addition, we used a single catheter material and did not investigate other materials. Polyurethane is consi- 
dered the most robust material for an epidural catheter [9]. However, even catheters made of different materials that are considered less sturdy than polyurethane need to have a sufficiently large FB to tolerate daily clinical use, and further investigations are necessary in the future.

Catheter rupture is thought to be associated with excessive extension of the catheter being clamped by the lamina, osteophyte, and occasionally strained muscles during removal. At the time of insertion, the catheter may be cut when the needle is pushed or rotated into the vertebral body or the lamina with the catheter out from the tip of the needle. The characteristics of the broken catheter may explain the mechanism of its breakage. The catheter is stretched when it breaks during removal, but it is not stretched when it breaks during insertion [7]. Although catheter breakage at the time of catheter insertion is rare, damage can cause catheter rupture during its withdrawal.

\section{Conclusion}

In conclusion, treatment of the heel of the epidural needle bevel, especially blasting treatment, can significantly increase the cutting force for the catheter and is important for the prevention of catheter rupture and damage.

\section{Acknowledgements}

We would like to thank the Unisys Corporation for producing and providing us needles we used in this study.

\section{Conflicts of Interest}

The authors declare no conflicts of interest regarding the publication of this paper.

\section{References}

[1] Bonica, J.J., Backup, P.H., Anderson, C.E., Hadfield, D., Crepps, W.F. and Monk, B.F. (1957) Peridural Block: Analysis of 3,637 Cases and a Review. Anesthesiology, 18, 723-784. https://doi.org/10.1097/00000542-195709000-00008

[2] von Hosslin, T., Imboden, P., Luthi, A., Rozanski, M.J., Schnider, T.W. and Filipovic, M. (2016) Adverse Events of Postoperative Thoracic Epidural Analgesia: A Retrospective Analysis of 7273 Cases in a Tertiary Care Teaching Hospital. European Journal of Anaesthesiology, 33, 708-714. https://doi.org/10.1097/EJA.0000000000000446

[3] Mitra, R. and Fleischmann, K. (2007) Management of the Sheared Epidural Catheter: Is Surgical Extraction Really Necessary? Journal of Clinical Anesthesia, 19, 310-314. https://doi.org/10.1016/j.jclinane.2006.11.005

[4] Lee, Y.H., Hwang, H.Y., Sim, W.S., Yang, M. and Lee, C.J. (2010) Breakage of a Thoracic Epidural Catheter during Its Removal-A Case Report. Korean Journal of Anesthesiology, 58, 569-572. https://doi.org/10.4097/kjae.2010.58.6.569

[5] Al-Kayed, O., Al-Bouti, F. and Ababneh, M.O. (2008) Surgical Removal of a Looped and Knotted Epidural Catheter in A Postpartum Patient-A Case Report. Middle East Journal of Anesthesiology, 19, 913-918. 
[6] Hobaika, A.B. (2008) Breakage of Epidural Catheters: Etiology, Prevention, and Management. Revista brasileira de anestesiologia, 58, 227-233.

https://doi.org/10.1590/S0034-70942008000300005

[7] Collier, C. (2000) Epidural Catheter Breakage: A Possible Mechanism. International Journal of Obstetric Anesthesia, 9, 87-93. https://doi.org/10.1054/ijoa.1999.0354

[8] Suzuki, T., Ito, K., Nishiyama, J., Hasegawa, K., Kanazawa, M. and Fukuyama, H. (2006) Development of a Safe Guide Wire. Journal of Anesthesia, 20, 64-67. https://doi.org/10.1007/s00540-005-0361-x

[9] Ates, Y., Yucesoy, C.A., Unlu, M.A., Saygin, B. and Akkas, N. (2000) The Mechanical Properties of Intact and Traumatized Epidural Catheters. Anesthesia \& Analgesia, 90, 393-399. https://doi.org/10.1213/00000539-200002000-00029 